\title{
An Analysis Of The Interest Elasticity Of Financial Asset Holdings By Income
}

Brian Amick, American Express, Phoenix

James M. McGibany, (E-mail: james.mcgibany@marquette.edu), Marquette University

\begin{abstract}
A Keynesian money demand model is used to examine the interest elasticity of financial asset holdings by income level. In this model, once an individual receives income, they first make transactions, and any leftover income goes for speculative purposes. Since only speculative balances are assumed to change with interest rates, individuals with income used mainly for transactions purposes are theorized to have asset holdings that are unresponsive to interest rates, while higher income individuals with speculative balances are expected to be more responsive to interest rates. The results support the Keynesian model, as lower income households are found to have the smallest interest elasticity, and the estimated elasticity rises with income.
\end{abstract}

\section{Introduction}

J here have been several examinations of the composition of money demand. Two of the most famous of these studies are Keynes' (1936) liquidity preference and Friedman's (1956) restatement of the quantity theory. A critical difference between the two deals with the influence of interest rates on money demand. Most studies since Laidler (1966) and Chow (1966) have concluded, unlike Friedman, that money demand is sensitive to interest rates, even though the framework of Friedman's model is more appropriate in today's banking environment than that found in Keynes' explanation, since demand deposits can earn some return.

Presently, researchers are more concerned with the stability of money demand in order to conduct sound monetary policy. Until the early 1970's, Goldfeld (1973) showed that liquid definitions of money, such as M1, seemed to accu-

Readers with comments or questions are encouraged to contact the authors via e-mail. rately predict economic activity, however, this changed when basic money demand models began to over-predict actual M1. Various reasons for the instability of M1 money demand models were postulated, including financial innovations, the increased use of electronic and computer technology, and high inflation. Recently, Hetzel (1992) and Mehra (1993) found M2 to be a relatively stable predictor of economic activity in the 1980's, however M2 growth has since slowed while economic growth has not. Thus, research focusing on trying to find a stable and predictable money demand function continues.

A topic where there is little or no current research is the interest elasticity of money and financial asset holdings for different economic situations, such as that for different levels of household income. For example, one may wish to determine, holding all else fixed, if the interest elasticity of money demand varies across individuals with different income. The main obstacle preventing more research in this area lies in the fact that decomposing the macroeconomic 
data is difficult, thus household-level or panel data are needed. Studies that use cross sectional data for money demand models include Mulligan (1997), Fujiki and Mulligan (1996), Bomberger (1993), Gale, Shen and Lu (1989), and Radecki and Garver (1987). All agree that but a small amount of literature exists due to the difficulty of obtaining individual household or firm data.

The household level data for this paper are extracted from the National Longitudinal Survey of Youth. The use of this data requires a modification to the definition of the monetary asset. Most analyses of money demand use a type of money that earns little or no interest, such as M1 or M2. However, this study uses a monetary asset variable that is expected to be positively related to interest rates, given the inclusion of less liquid forms of financial assets. Four years of data are analyzed making it is possible to examine how changes in interest rates over time affect financial asset holdings across households with different incomes. In addition, a simple test is employed to determine if the relative stability of one's income over time is a factor in determining the responsiveness of asset holding with respect to changes in interest rates. The results show that the interest elasticity of financial asset holdings increases with income.

The paper is organized as follows. The next section gives theoretical considerations on how the interest elasticity of monetary asset holdings changes with different income levels. In addition, the use of panel data allows sociodemographic variables to be examined, which should influence asset holdings. This section also addresses the interest elasticity of asset holdings for individuals for varying degrees of income stability in relation to the permanent income hypothesis. Section III describes the data, its possible limitations, and the expected signs for the explanatory variables. Section IV describes the empirical model, discusses how income is categorized and provides results on how interest rates affect financial asset holdings for different income levels. The final section reviews the re- sults and offers suggestions for future research.

\section{Theoretical Considerations and Literature Re- view}

Interest Elasticity for Different Levels of Income.

The theoretical model used in this study follows that of Keynes (1936) in that it breaks down the elements of money holdings between transactions $^{1}$ and speculative balances. This breakdown can be thought as a two-tiered process. Once an individual receives her/his income, she/he first makes transactions on goods and services. Any remaining income, i.e. savings, can then be divided into two categories, a liquid type of money (such as M1), which earns little or no interest, and a more illiquid type of money, which earns a higher rate of interest than the liquid money.

The model assumes a given level of household income. Some households may not reach the second tier, thus all income is used for trans. action purposes. The rest of households reach the second tier, meaning that they will have some speculative balances. For simplicity, it is assumed that individuals reaching the second tier have the same marginal propensity to consume regardless of their income level. That is to say, the higher the income, a person will have both higher levels of transactions and speculative balances, but at the same proportionate level as others that reach the second tier. The next part of the model determines in which form individuals that reach the second tier hold their speculative balances.

Once a person reaches the second tier, a decision is needed to determine how to allocate the speculative balances between assets. Baumol (1952) and Tobin (1956) show that the choice between the liquid asset and the less liquid asset not only differs on their degree of liquidity and rate of return, but in several other ways, most dealing with higher transaction costs (either dollar amounts or time costs) for the less liquid asset. Differences in costs between the two assets 
can be the actual cost realized in the process of buying either asset. For example, starting a checking account at a banking institution typically requires less time than taking part in the next auction for long-term bonds, and the fees to do so are smaller than the fees to set up an account with a brokerage service. Another factor that may play a role when determining the amount and type of financial assets to hold is the existence of an early withdraw penalty. The purpose of these examples is to show that buying a less liquid asset that bears more interest is likely to have more transaction costs than buying a more liquid asset. These findings and assumptions can now be used to theorizing how individuals with varying amounts of income that reach the second tier will allocate their speculative balances.

Even though someone may accumulate enough income for speculative purposes, that individual may still choose to hold the liquid asset over one that has a higher rate of return. The costs of acquiring the higher interest-bearing asset might offset the higher earnings that may be achieved. Thus, for those with speculative balances, it is possible that the impact of changes in interest rates on assets holdings vary as well. In conclusion, a person whose income is solely used for transactions is theorized to have money demand (financial asset holdings) that is (that are) interest inelastic, while individuals who reach income levels for speculative demand can be separated into two categories. The first is such that the costs of obtaining the higher interest bearing asset is more than the potential extra earnings from that asset, and second is such that the reverse holds. In other words, higher transaction costs lead to more liquid assets held, all else fixed, while higher returns lead to more interest-bearing assets held, all else fixed. However, as interest rates rise, more and more individuals will hold interest-bearing assets, making the demand for liquid money assets fall.

Given the difficulty of collecting reliable household data, studies that have investigated money demand for individual households have been limited. However, three such studies which analyze various aspects of money demand at the household level are Radecki and Garver (1987), Gale, Shen and Lu (1989) and Bomberger (1993). ${ }^{2}$ The latter study focused primarily on individual's M1 holdings with relation to their income and wealth. As expected, both scale variables are positively related to demand deposits, but the author concludes that wealth is more of a determinant of M1 holdings than previous time-series estimates have suggested. Gale, Shen and Lu (1989), using data from the 1983 University of Michigan survey of households, found that the income elasticity of demand for M1 is positive and significant, but its magnitude varies based on the age of the head of household as well as how frequently the household receives income payments.

The focus of Radecki and Garver (1987) is similar to that of the present study. Using the University of Michigan survey data from 1984 , they estimated an empirical model of demand deposit holdings by household. Variables of interest in their model included the frequency of pay periods per month, the number of full-time workers in the household, fees for accounts, and the interest rate on checking accounts. Their primary finding showed that the opportunity cost variable, defined as the average national money market interest rate less the rate earned on the household's checking account, was negatively related to demand deposit holdings. It is important to note that their study used data from only one point in time, thus there is little variation of the opportunity cost variable over the sample. They also found that households hold fewer checking deposit balances if they are paid more than one time per month, have more than one full-time worker in household, and have low credit card balances.

There has been no research that directly investigates the interest elasticity of money demand by income level for individual households over time. However, Butkiewicz and McCon- 
nell (1995) indirectly encountered this issue. Their paper used quarterly flow of funds data from 1952 to 1990 to explain money demand for the household and business sectors. Even though their error-correction models faced parameter inconsistencies, most likely due to financial deregulation in the early 1980 's, they found that the two sectors to have statistically different interest elasticities of (M1) money demand. Their results indicated that the one-period lagged threemonth Treasury bill rate was negative and statistically significant when explaining money demand for the business sector, however it was not statistically significant when explaining the household sector. In both sectors, the income variable (real gross national product for the business, real disposable personal income for the household sector) was found to be positive and significant.

Concerning the difference of statistical significance of the interest rate variable between the household and business sectors, there are several possible explanations. One is that before banking deregulation in the early 1980's, individuals may have been more constrained than businesses in the type of asset choices that were available to them, thus households might have been less responsive to interest rates. Another explanation, which is related to the previous, may add support to the theory set forth in the present study. If one assumes that the average income level in the business sector is greater than income per household, it may suggest that businesses to have a higher level of speculative demand, thus businesses would likely be more responsive to the prevailing interest rate. The last explanation may be related to the first in that businesses may have been able to invest in assets that households could not, strictly due to the magnitude of income needed for those types of financial investments.

\section{Other Household Influences on Financial Asset Holdings}

Holding income and interest rates fixed, other characteristics should play a role in determining the size of the financial asset holdings of households. These variables include educational attainment, family size, ownership of real estate, whether or not someone in the household is selfemployed, the household's current employment situation, marital status, the frequency of income receipts, and the household's area of residence.

In a cross-sectional study using data from 1983 from the Survey of Consumer Finances, Duca and Whitesell (1995) found that interest rates and income are not the only factors that influenced savings. Since the primary focus of their article was a qualitative choice model that investigated the characteristics of a person who owned a credit card, they give little attention to the results of their money demand model. However, they provided results from a regression model that used passbook savings as the dependent variable and employment, precautionary savings, and sociodemographic measures as independent variables. As expected, they found income to be positively related with passbook savings balances.

However, among their other findings was that married households and those owning their own home hold fewer savings balances. The authors justified the latter result by arguing that home owners may use home equity as a store of wealth while non-home owners use other forms of savings, such as savings account balances, for this purpose. While they gave no explanation on why passbook savings are negatively related with the marital status of an individual, it is expected that the marriage variable may signify that the individual has children and/or they are in the process of buying physical assets. If this is the case, more of the household's income goes for transactions purposes, or a large share of their wealth is held as physical, rather than financial, assets.

\section{Stability of Income}

A topic somewhat related to the interest rate 
elasticity of money balances is the permanent income theory attributed to Friedman (1956). This theory suggests that individuals budget their consumption and saving decisions on their expected lifetime income. Thus, perceived short-term changes such as decreased interest rates, which lower current income from wealth, would have little influence on a person's current consumption behavior. This theory has generated many debates with conflicting findings. Fuhrer (1992), using aggregate data, found that an expansionary monetary policy that lowered interest rates was met by increased consumption on durable goods and motor vehicles. This is contrary to the permanent income theory, which says that the individual would internalize the interest rate change on her/his income and wealth portfolio over their expected lifetimes.

On the other hand, Runkle (1991) failed to reject the permanent income theory using panel data. He states that aggregate studies suggest that individuals make their expectations using macroeconomic variables, however, these variables could have little influence in determining a household's future conditions. Runkle also disproved the notion of liquidity constraints, which is a major criticism of the permanent income theory. Those that reject the permanent income theory suggest that liquidity constraints disallow individuals to borrow or lend freely to accommodate their lifetime savings behavior, making them less sensitive to interest rate changes.

In regards to interest elasticity of financial asset holdings for households with different degrees of income stability, it is theorized that respondents with more stable incomes will be more interest sensitive. Stable incomes allow for a more steady consumption path, thus deviations from this path can be altered or budgeted to suit current economic conditions. For example, if interest rates and income from asset holdings rise, and assuming this is expected to be a temporary phenomenon, consumers with stable income will not increase consumption by a large amount. Therefore, this increased income from wealth will result in more financial assets held. On the other hand, individuals with unstable incomes accumulate financial assets when their income peaks, and consume from wealth as income declines. In addition, the financial assets for such individuals are more apt to be kept liquid to compensate for future consumption needs if income falls. A temporary increase in income from financial asset holdings is more likely to be used for consumption purposes in households such as these, rather than a subsequent increase in holdings of the financial assets. This suggests that an increase in interest rates for households with stable incomes will have a larger impact on financial asset holdings, relative to those households with less stable incomes.

\section{Data}

The data for this paper was extracted from the National Longitudinal Survey of Youth (NLSY). One potential drawback of this sample is the age group it represents. Individuals in the sample are between the ages of 25 to 33 , thus it is likely that their incomes and assets will not be representative of the entire population. Nonetheless, approximately 1600 individuals were randomly chosen over the four-year span of 1987 to 1990. This time period was selected, as it is the longest consecutive years of data on asset holdings in the survey, in addition to being a period of substantial variability of interest rates. However, the sample size was reduced to just 411 households due to missing data, extremely low or unreported values of income, refusal to answer certain questions with respect to household or personal characteristics, and other unreliable data that did not coincide to responses of previous and/or subsequent years.

The variables that are used in this study and their definitions can be found in Table 1. The dependent variable is the natural log of total financial assets of the household, ZTAST, and includes savings and checking accounts, money market funds, United States savings bonds, certificates of deposit, common stock, corporate 
bonds, mutual funds, rights to estate or invest. ment trust, and personal loans that are owned by the respondent. Instead of a more traditional short-term rate, a rate constructed by Mehra (1992) is used. It is the own rate of return on M2 assets, RM2, constructed as a weighted average of rates on assets in M2, and varies annually. Given that M2 and ZTAST have many components in common, the use of this rate is intended to approximate the rate of return on ZTAST.

Concerning the expected signs of the independent variables, both ZTINC, the log of household income, and RM2 have positive expected signs, which says that higher income or higher interest rates each lead to an increased holding of financial assets. Unlike traditional money demand models, this interest rate variable is expected to be positively related with financial asset holdings. Money demand models usually show substitution out of the money asset when interest rates rise, however in this model as RM2 rises, individuals should increase their holdings of financial assets, since RM2 represents the own rate of return on financial assets.

Many of the demographic variables may be correlated with income. For example, the highest-grade completed variable, HGC, has a positive expected sign although it may be correlated to income. Additionally, individuals with higher educational attainment may be more aware of alternative savings opportunities that may increase financial asset holdings relative to other types of assets. Marital status, MSTAT, and family size, FAMSZ, are expected to have a negative effect on ZTAST, as it is postulated that, all else fixed, married respondents and those with larger families will have greater consumption needs and

Table 1

Variable definition and expected signs

Variable

ZTAST

RM2

OC

ZTINC

HOUSE

$\mathrm{HGC}$

FAMSZ

MSTAT

CLSWORK

WKSUNEM
Definition

Dependent Variable. Natural log of total assets of household (savings accounts, bonds, stocks, money market funds, certificates of deposit, etc.)

Interest rate on $\mathrm{M} 2$.

Rate of return on home equity minus RM2.

Natural log of total family income.

Own or making payments on a house, 1 yes and 0 no.

Highest grade completed.

Total number of family members.

Marital status, 1 if married and 0 otherwise.

Class of worker, 1 if respondent is employed by a private company or the government and 0 if self-employed.

Number of weeks unemployed for the past year.

Predicted Sign

$+$

$+$

$+$

$?$ 
hold a larger proportional share of physical, rather than financial, assets. HOUSE, which is a qualitative variable that is 1 if the respondent owns or is making payment on a home, and 0 otherwise, is expected to have a negative influence on asset holdings because individuals might consider home equity as an alternative form of wealth. The worker class variable, CLSWORK, which is 1 if the respondent is employed by a private company or government, and 0 if selfemployed, has a negative expected sign given the fact that self-employed individuals own their own business, thus are likely to hold more assets of all types and financial assets in particular. The variable, weeks out of the labor force, WKSUNEM, is given no expected signs. As this variable increases, it may signal that the respondent has enough assets to afford to be unemployed, thus a positive sign is expected, on the other hand, lengthy unemployment could mean any financial assets that were previously held have been drawn down.

\section{Empirical Results}

First, a specification similar to that of a simple money demand model is estimated that regresses the dependent variable, ZTAST, on the natural log of income, ZTINC, and the own rate of return variable, $\mathrm{RM} 2$.
(1) ZTASTit $_{\text {ZTA }}$ a $+\mathrm{a}_{2}$ ZTINC $_{\mathrm{it}}+\mathrm{a}_{3} \mathrm{RM}_{2 \mathrm{t}}$ $\mathrm{i}=1-411$ and $\mathrm{t}=1987,1988,1989,1990$

The results show that RM2 is positive, however statistically insignificant, while income is positive and statistically significant at the $1 \%$ level. These results can be found in Table 2, equation $1 .^{3}$

Next, the following equation is estimated over the entire pooled sample, controlling for the individual's personal characteristics. ${ }^{4}$
(2) ZTASTit $=\mathrm{b}_{1}+\mathrm{b}_{2}$ ZTINC $_{\mathrm{it}}+\mathrm{b}_{3} \mathrm{RM}_{2}$

$+b_{4} H_{0 O U S E}+b_{5} H_{i t} C_{i t}$

$+b_{6} F_{A M S Z}+b_{7} C_{1}$ SWORK

$+b_{8} W K S U N E M i t$

$\mathrm{i}=1-411$ and

$\mathrm{t}=1987,1988,1989,1990$

Concerning the results (Table 2, equation 2), the coefficient of ZTINC is positive and statistically significant, as expected, and according to the estimated equation, a $1 \%$ increase in income results, on average, in an increase of asset holdings by $1.35 \%$. The estimated coefficient of RM2 is positive but statistically insignificant. The coefficients of educational attainment, HGC, and family size, FAMSZ, are statistically significant and both carry the expected sign, while the dummy variable for whether the head of household is self-employed is negative, as expected, but significant only at lower levels of confidence. The results show that an increase of one family member decreases holdings of financial assets by $21.8 \%$ on average, and selfemployed individuals have $25.5 \%$ more financial assets, on average, than other individuals. HOUSE was expected to be negative, however, its estimated coefficient is positive and significant. This says that home owners are not only saving via home equity but in other forms. The coefficient of weeks out of the labor force variable, WKSUNEM, is found not to be significant. $^{5}$

The next step is to determine whether or not interest elasticity of financial asset holdings is different for different levels of income. For that purpose, the following equation is estimated:

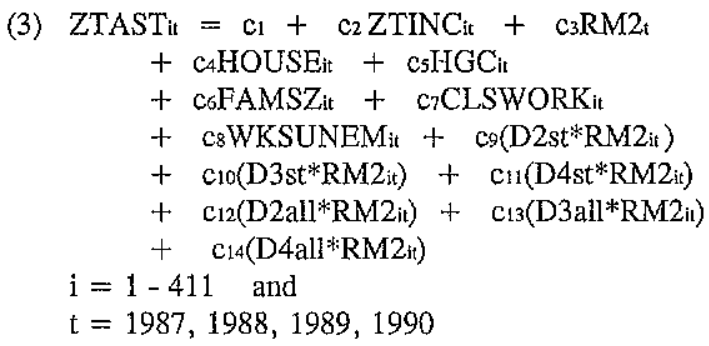


Table 2

Regression estimates for Equations (1) - (3)

( $t$-statistics in parentheses)

\begin{tabular}{|c|c|c|c|}
\hline Variable & Equation 1 & Equation 2 & Equation 3 \\
\hline $\mathrm{RM} 2$ & $\begin{array}{l}0.067 \\
(0.93)\end{array}$ & $\begin{array}{l}0.040 \\
(0.57)\end{array}$ & $\begin{array}{l}0.030 \\
(0.42)\end{array}$ \\
\hline ZTINC & $\begin{array}{l}1.291 \\
(20.63)\end{array}$ & $\begin{array}{l}1.352 \\
(19.61)\end{array}$ & $\begin{array}{l}0.997 \\
(10.53)\end{array}$ \\
\hline HOUSE & & $\begin{array}{l}0.268 \\
(3.67)\end{array}$ & $\begin{array}{l}0.228 \\
(3.12)\end{array}$ \\
\hline $\mathrm{HGC}$ & & $\begin{array}{l}0.095 \\
(5.67)\end{array}$ & $\begin{array}{l}0.087 \\
(5.21)\end{array}$ \\
\hline FAMSZ & & $\begin{array}{l}-0.218 \\
(-7.68)\end{array}$ & $\begin{array}{l}-0.209 \\
(-7.37)\end{array}$ \\
\hline CLSWORK & & $\begin{array}{l}-0.255 \\
(-1.56)\end{array}$ & $\begin{array}{l}-0.215 \\
(-1.32)\end{array}$ \\
\hline WKSUNEM & & $\begin{array}{l}-0.001 \\
(-0.11)\end{array}$ & $\begin{array}{l}-0.001 \\
(-0.22)\end{array}$ \\
\hline D2st*RM2 & & & $\begin{array}{l}0.004 \\
(0.28)\end{array}$ \\
\hline D3st*RM2 & & & $\begin{array}{l}0.036 \\
(2.35)\end{array}$ \\
\hline $\mathrm{D} 4 \mathrm{st} * \mathrm{RM} 2$ & & & $\begin{array}{l}0.078 \\
(4.49)\end{array}$ \\
\hline D2all*RM2 & & & $\begin{array}{l}0.055 \\
(1.80)\end{array}$ \\
\hline D3all*RM2 & & & $\begin{array}{l}0.102 \\
(3.03)\end{array}$ \\
\hline D4all*RM2 & & & $\begin{array}{l}0.139 \\
(4.37)\end{array}$ \\
\hline intercept & $\begin{array}{l}-6.012 \\
(-8.32)\end{array}$ & $\begin{array}{l}-7.132 \\
(-9.12)\end{array}$ & $\begin{array}{l}-3.694 \\
(-3.69)\end{array}$ \\
\hline $\mathrm{R}^{2}$ adj. & $\begin{array}{l}21.1 \% \\
1644\end{array}$ & $\begin{array}{l}26.8 \% \\
1644\end{array}$ & $28.3 \%$ \\
\hline
\end{tabular}

In this specification, for any individual, D2 $=1$ if ZTINC is in the 2nd quartile for any given year, D2 $=0$, otherwise; D3 $=1$ if ZTINC is in the 3rd quartile for any given year, D3 $=0$ otherwise; and D4 = 1 if ZTINC is in the 4th quartile for any given year, $\mathrm{D} 4=0$ otherwise. Then, with (n) running from 2 to $4, D(n) s t=1$ if ZTINC falls in that quartile any of the given years, $D(n)$ st $=0 \quad$ otherwise and $D(n)$ all $=1$ if
ZTINC always lies in that quartile each year of the sample, $\mathrm{D}(\mathrm{n})$ all $=0$ otherwise.

The decomposition of incomes into separate quartiles in this fashion helps to show the interest elasticity of respondents with differing income levels and income level stability. In equation (3), the coefficient of RM2 represents the interest elasticity of financial asset holdings for a per- 
son whose income is always in quartile one, while, for example, the coefficient of D(3)all*RM2 represents the difference between that elasticity and the interest elasticity of asset holdings for respondents who are always in the third income quartile. On the other hand, the coefficient of $\mathrm{D}(3) \mathrm{st} * \mathrm{RM} 2$ represents the difference between the interest elasticities of financial asset holdings for respondents that are sometimes in the third quartile compared to individuals in the lowest income quartile.

The estimation results of the previous equation can be found in Table 2, equation 3. The estimated signs and significance of the household characteristic variables are similar to those for equation (2) previously discussed. Concerning the decomposition of incomes into different quartiles, the results show that respondents with incomes always in the first or second quartiles, or that are sometimes in the second or third quartile, have interest elasticities that statistically not different from zero. The test results that show the overall interest elasticity of financial asset holdings are shown in Table 3. Recall that the theory suggests that households with low income are more likely to spend much if not all of their income for transactions purposes. Therefore, lower income households are likely to have little, if any, speculative balances, and should have very little reaction to changes in interest rates.

On the other hand, from Table 3, respondents who are sometimes in the fourth (highest) income quartile have estimated interest sensitivities that are positive and significant with a pvalue of 0.13 . In addition, individuals that are always in the third quartile or always in the fourth quartile have estimated interest elasticities that positive and significant with p-values of 0.08 and 0.02 , respectively. As hypothesized, the magnitude of the coefficients in Table 3 that are calculated for tests $2 \mathrm{a}-4 \mathrm{a}$ and $2 \mathrm{~b}-4 \mathrm{~b}$ clearly show that individuals with higher income levels are increasingly responsive to interest rate changes; this holds true for whether a respondent

Table 3

Significance Tests for the Elasticity of RM2 with respect to ZTAST by Income Level (from Equation 3, Table 2)

( $t$-statistics in parentheses)

TEST 1 Overall Elasticity of households in lowest income quartile:

$$
\begin{array}{ll}
\mathrm{RM} 2=0 & \text { Calculated elasticity }=0.030
\end{array}
$$

TEST 2a Overall Elasticity of households sometimes in 2nd quartile:

$$
\mathrm{RM} 2+\mathrm{D} 2 \mathrm{st} * \mathrm{RM} 2=0 \quad \text { Calculated elasticity }=0.034
$$

TEST 3a Overall Elasticity of households sometimes in 3rd quartile:

$$
\mathrm{RM} 2+\mathrm{D} 3 \mathrm{st}^{*} \mathrm{RM} 2=0 \quad \text { Calculated elasticity }=0.065
$$

TEST 4a Overall Elasticity of households sometimes in 4th quartile:

$$
\mathrm{RM} 2+\mathrm{D} 4 \mathrm{st} * \mathrm{RM} 2=0 \quad \text { Calculated elasticity }=0.107
$$

TEST $2 b$ Overall Elasticity of households always in 2nd quartile:

$$
\mathrm{RM} 2+\mathrm{D} 2 \text { all } * \mathrm{RM} 2=0 \quad \text { Calculated elasticity }=0.084
$$

TEST 3b Overall Elasticity of households always in 3rd quartile:

$$
\mathrm{RM} 2+\mathrm{D} 3 \text { st } * \mathrm{RM} 2=0 \quad \text { Calculated elasticity }=0.132
$$

TEST 4b Overall Elasticity of households always in 4th quartile:

$$
\mathrm{RM} 2+\mathrm{D} 4 \mathrm{st} * \mathrm{RM} 2=0 \quad \text { Calculated elasticity }=0.169
$$


is always in a given income quartile or whether she/he fluctuates among income quartiles. ${ }^{6}$ For example, a person who is sometimes in income quartile four will increase financial asset holdings, on average, by $4.2 \%$ more than a person who is sometimes in the $50 \%-75 \%$ (third) income quartile, given a one percentage point increase in RM2. On the other hand, a person always in the fourth income quartile will increase asset holdings, on average, by $3.7 \%$ more than a person always in the 3rd income quartile, given the same interest rate move.

The previous results also show that there is a distinct difference in saving patterns for individuals who seem to have a stable income. Individuals who are always in a certain income quartile are more likely to respond to changes in the short-term interest rate. While these results are as expected, given that this sample covers but four years of observations, any discussion of a set of statistical results either conforming to or rejecting the permanent income theory must be discounted accordingly.

\section{Conclusions}

This paper examines the interest elasticity of financial asset holdings for individuals using the NLSY data set. Unlike most money demand type models, where one substitutes away from money when interest rates rise, the model presented in this study finds, as expected, a positive relationship between the rate of return of $\mathrm{M} 2$, RM2, and the financial asset variable extracted from the survey. Individuals were placed into different quartiles based on their incomes and whether they were sometimes or always in a given quartile of the sample over the period. The results show that individuals who are always in the lowest income quartile have an interest elasticity of financial assets that is not statistically different from zero. However, this elasticity incrementally rises for individuals that are in higher income quartiles. In addition, when comparing whether a person was sometimes or always in a given quartile, individuals that are always in a given quartile are more interest responsive than those that switched between quartiles over the sample. This result leads to the conclusion that for this sample, individuals with stable incomes are more responsive to interest rate changes than those whose income varies substantially.

In conclusion, the primary result of this paper found that individuals with higher and more stable incomes are more responsive to interest rate changes with respect to their holdings of financial assets. The difference in responsiveness can be partly explained by the fact that lower income households may have enough income for transaction purposes only. However, differences in the interest elasticity remain between individuals with differing levels of speculative balances. These differences can be possibly explained by liquidity constraints, transaction costs that outweigh possible earning returns, availability to certain investments, and saving attitudes.

\section{Suggestions for Future Research}

There are two logical extensions of this study. The first would be to determine if the results obtained here using the sample of young household found in the NLYS can be generalized for a larger segment of the population. While it may be that younger individuals with lower incomes behave substantially different than their higher income cohorts in terms of interest rate responsiveness, this difference may be less pronounced when examining the entire population. The second extension would be to determine if the difference in interest elasticities between higher and lower income households extends to other assets. For example, many believe that interest rate policies by the central bank influence consumption and investment decisions, especially in the real estate market. It may be that the interest rate induced changes to this market are mainly due to the fact that they affect higher income individuals, or the major impacts of changing interest rates on the real estate markets show up primarily in high income areas. 
- Precautionary balances, a third component of Keynes' analysis can be combined with transaction balances.

- Fujiki and Mulligan (1996) analyze money demand using a sample of Japanese households. That study is similar to that of Bomberger (1993), in that is analyzes crosssectional data only.

- An alternate specification was estimated using an opportunity cost variable in place of the own rate of return approximation in Equation 1. The opportunity cost variable, OC, was constructed by calculating the rate of growth of the average sales price of existing homes in each year, and subtracting from it RM2. Since physical assets, such as real estate, are not part of the dependent variable, one expects that as the return to physical assets rises relative to the return on financial assets, holdings of financial assets will fall. As expected, the estimated coefficient of $\mathrm{OC}$ is negative and significant in this alternate specification.

- Marital Status (MSTAT) and family size (FAMSZ) were found to be highly collinear. A model with MSTAT included was found to have results generally consistent with those reported in Table II, Equation (2), except that FAMSZ, while negative, was significant with p-value 0.18 .

- An alternative specification of Equation 2, replacing the own rate variable, RM2, with the opportunity cost variable, $\mathrm{OC}$, was estimated. The estimated coefficient of $\mathrm{OC}$, is negative and significant with a p-value of 0.095 , while the estimated coefficients of the remaining independent variables are virtually identical to those reported in Table II, equation 2 .

This conclusion also holds, in general, when using the alternative interest rate specification, OC. As income rises from the lowest to highest quartile, households are increasingly (in absolute value) more responsive to changes in $\mathrm{OC}$, although not significantly except those that are always in the highest income quartile.

\section{References}

1. Baumol, William, "The Transactions Demand for Cash: An Inventory Theoretic Approach," Quarterly Journal of Economics, Vol. 66, pp. 545-556, 1952.

2. Bomberger, William A., "Income, Wealth, and Household Demand for Deposits," The American Economic Review, 83, pp. 1034. 1044, 1983.

3. Butkiewicz, James and McConnell, Mary, "The Stability of the Demand for Money and M1 Velocity: Evidence from the Sectoral Data," The Quarterly Review of Economics and Finance, Vol. 35, pp. 233-244, 1995.

4. Chow, Gregory, "On the Short-Run and Long-Run Demand for Money," Journal of Political Economy, Vol. 74, pp. 111-131, 1966.

5. Duca, John and Whitesell, William, "Credit Cards and Money Demand: A Crosssectional Study," Journal of Money, Credit and Banking, Vol. 27, pp. 604-623, 1995.

6. Friedman, Milton, "The Quantity Theory of Money: A Restatement." Studies in the Quantity Theory of Money, Chicago, IL: The University of Chicago Press, pp. 3-21, 1956.

7. Friedman, Milton, A Theory of the Consumption Function, Princeton, NJ: Princeton University Press, 1957.

8. Fuhrer, Jeffrey C, "Do Consumers Behave as the Life-Cycle/Permanent-Income Theory of Consumption Predicts?" Federal Reserve Bank of Boston New England Economic Review, September/October, pp. 3-14, 1992.

9. Fujiki, Hiroshi and Casey B. Mulligan, "A Structural Analysis of Money Demand: Cross-Sectional Evidence from Japan," Bank of Japan Monetary and Economic Studies, Vol. 14, pp. 53-78, 1996.

10. Goldfeld, Stephen, "The Demand for Money Revisited," Brookings Papers on Economic Activity, Vol. 3, pp. 577-638, 1973.

11. Hetzel, Robert L., "How Useful is M2 To- 
day?" Federal Reserve Bank of Richmond Economic Review, September/October, pp. 12-26, 1992.

12. Keynes, John M., The General Theory of Employment, Interest, and Money, New York and London: Harcourt Brace Jovanovich, 1936.

13. Laidler, David, "The Rate of Interest and the Demand for Money-Some Empirical Evidence," Journal of Political Economy, Vol. 74, pp. 545-555, 1966.

14. Mehra, Yash P., "Has M2 Demand Become Unstable?" Federal Reserve Bank of Richmond Economic Review, September/ October, pp. 27-35, 1992.

15. Mehra, Yash P., "The Stability of the M2 Demand Function: Evidence from an ErrorCorrection Model," Journal of Money, Credit, and Banking, Vol. 25, pp. 455-460, 1993.

16. Mulligan, Casey B., "Scale Economies, the
Value of Time, and the Demand for Money: Longitudinal Evidence from Firms," Journal of Political Economy, Vol. 105, pp. 1061-1079, 1997.

17. The National Longitudinal Youth Survey, Ohio State University, Center for Human Resource Research, 1995.

18. Radecki, Lawrence J. and Garver, Cecily C., "The Household Demand for Money: Estimates from Cross-sectional Data," Federal Reserve Bank of New York Quarterly Review, Spring, pp. 29-34, 1987.

19. Runkle, David E. "Liquidity Constraints and the Permanent-Income Hypothesis, Evidence from Panel Data," Journal of Monetary Economics, Vol. 27, pp. 73-98, 1991.

20. Tobin, James, "The Interest Elasticity of the Transactions Demand for Cash," Review of Economics and Statistics, Vol. 38, pp. 241247, 1956. 